\title{
Study of Risk Factors of Coronary Artery Disease with Special Reference to Homocysteine
}

\author{
Yagna Sreenija ${ }^{1}$, Dr. Naveen Kumar Sambu ${ }^{2 *}$, Dr. Durga Prasad Kedam ${ }^{3}$, Dr. Havilah Polur ${ }^{4}$ \\ ${ }^{1}$ Phase III MBBS, Santhiram Medical College \& General Hospital, NH-18, Nandyal, Kurnool, Andhra Pradesh 518112, India \\ ${ }^{2}$ Assistant Professor, Dept of Biochemistry, Santhiram Medical College \& General Hospital, NH-18, Nandyal, Kurnool, Andhra Pradesh 518112, India \\ ${ }^{3}$ Professor \& Head, Dept of Biochemistry, Santhiram Medical College \& General Hospital, NH-18, Nandyal, Kurnool, Andhra Pradesh 518112, India \\ ${ }^{4}$ Professor, Dept of Biochemistry, Santhiram Medical College \& General Hospital, NH-18, Nandyal, Kurnool, Andhra Pradesh 518112, India
}

DOI: $\underline{10.36348 / \text { SIJB.2019.v02i09.004 }}$ | Received: $20.09 .2019 \mid$ Accepted: $27.09 .2019 \mid$ Published: 30.09 .2019

*Corresponding author: Dr. Naveen Kumar Sambu

\section{Abstract}

Background: Risk factor reduction is the primary clinical approach in preventing coronary artery disease. Traditional risk factors are found to be absent in many of the cases. Novel risk factor - hyper homocysteinemia was reported to be associated with the disease process. Objectives: This study is aimed at identifying the association of coronary artery disease with homocysteine and other conventional risk factors, along with the risk they pose both independently and in combination. Methods: The study included 100 people, 60 subjects in the study group with diagnosed coronary artery disease \& 40 subjects in the control group with no disease. Conventional risk factors are evaluated \& compared along with homocysteine levels. Results: The data obtained concludes that the levels of homocysteine independently are significantly higher $(20.19 \pm 5.00)$ among the study than the control group $(12.35 \pm 3.39)$.However, there was no significant association between conventional risk factors homocysteine levels and conventional risk factors (smoking, family history of coronary artery disease, hypertension and diabetes). Conclusion: Elevated levels of homocysteine are associated with coronary artery disease. Homocysteine, in combination with the conventional risk factors, did not pose any increased risk for the disease. Raised levels of Homocysteine in the controls is probably attributed to the early sign of disease occurrence, further investigation is required into this aspect. Also, an investigation is necessary to search for the ways of reduction of risk like vitamin supplementation.

Keywords: Homocysteine, Coronary artery disease, traditional risk factors.

Copyright @ 2019: This is an open-access article distributed under the terms of the Creative Commons Attribution license which permits unrestricted use, distribution, and reproduction in any medium for non-commercial use (NonCommercial, or CC-BY-NC) provided the original author and source are credited.

\section{INTRODUCTION}

Mortality \& morbidity from coronary artery diseases is a major health problem. Coronary artery disease has a high prevalence in Indians, which couldn't be explained by traditional risk factors alone [1]. To achieve the desired level of accuracy in prediction \& further prevention of disease novel risk factors like homocysteine, lipoprotein a, fibrinogen, hsCRP came into the scene [2]. Elevated levels of homocysteine are associated with various vascular diseases and are also considered an independent risk factor for coronary artery disease [3]. The role of Homocysteine as a risk factor has not been extensively studied in the Indian population. Due to dietary and other ethnic differences, data difference in the west need not necessarily be accurate for our population so more studies with ethnic or dietary variation are required. Recent reports on Homocysteine suggest that it is an independent prediction of vascular diseases, including stroke and Coronary Artery Disease [4]. But in contrast, some studies the absence of association of Homocysteine with Coronary Artery Disease like those that are conducted in Kerala and Vadodara [5, 6]. Thus the role of Homocysteine an independent risk factor is not clearly understood.

The effect of diet and ethnicity its level is not investigated thoroughly along with its relation with other risk factors. Hence, this study was done to evaluate the role of Homocysteine in Coronary Artery Disease and its relationship with conventional risk factors which include age, smoking, hypertension, diabetes, family history and obesity [7].

Homocysteine, a thiol-containing amino acid, is formed as an intermediate in the metabolism of methionine. The first step in the synthesis of homocysteine is the formation of SAM, a methyl donor from methionine. SAM is converted to $\mathrm{SAH}$, which is further hydrolyzed to yield homocysteine \& adenosine. 
Depending on whether there is a relative excess or a deficiency of methionine, homocysteine enters either transsulfuration or remethylation pathways. Abnormalities of these pathways due to either nutrient deficiencies or enzyme inactivity or genetic differences may result in the accumulation of homocysteine. Total homocysteine comprises of both free and protein-bound fraction, with $80 \%$ in the bound state [8]. The unbound fraction is susceptible to oxidation at physiological $\mathrm{pH}$ and may form a dimer, due to which oxidative damage to vascular endothelium \& LDL occurs leading to atherosclerosis [9]. Some studies also showed an association of increased thrombogenicity as a cause [10]. The levels are altered due to differences in ethnicity (genetic conditions) \& nutritional factors (folic acid levels) [11].

\section{MATERIALS AND METHODS}

The current study is an observational casecontrol study conducted in our hospital from July 2018 to October 2018. The study had 60 patients who had stenosis $(>70 \%)$ in one or more major epicardial arteries or had presented with acute coronary syndromes. The sample was collected within a day of the attack. The control group consists of 40 people who came for their yearly medical checkups with no previous IHD history. Exclusion Criteria includes Renal impairment, pregnancy, SIRS, lipid reducing agents. The study was approved from the ethics committee of our Institute. Patients were provided with complete information, and written consent is obtained. Diagnosis of diabetes is based on WHO criteria, i.e.; FBG $>126 \mathrm{mg} / \mathrm{dl}$ or postprandial glucose $>150 \mathrm{mg} / \mathrm{dl}$, similarly HTN > 140/90 mm.

\section{Biochemical Methods}

Homocysteine - Spectrophotometry, estimating total homocysteine levels PRINCIPLE: T(Hcy) ---- $\rightarrow$ ( Hcy ) Free in the presence of s-methyltransferase

Free Hcy+SAM----------------- $\longrightarrow$ Methionine + SAH in the presence of SAM hydrolase and adenosine deaminase

SAH+NADH --------------------- $\longrightarrow$ Inosine + NAD+ in the presence of glutamate

Dehydrogenase

A series of enzymatic reactions causing a decrease in absorbance value due to NADH oxidation to NAD+. Homocysteine concentration in the sample is directly proportional to the amount of NADH converted.

SPECIMEN: A minimum of 8 hours fasting is required as the food rich in amino acid methionine can grossly elevate the homocysteine levels. It is essential to centrifuge the samples immediately after collection to separate the serum from blood. If immediately centrifugation was not possible, the samples were kept in ice and centrifuged after an hour. Hemolysed and turbid specimens were not taken.

\begin{tabular}{|c|c|c|}
\hline \multicolumn{3}{|c|}{ Procedure parameters: two level calibration } \\
\hline REAGENT & CALIBRATOR & SAMPLE \\
\hline Reagent 1 & $500 \mu \mathrm{L}$ & $500 \mu$ \\
\hline Calibrators (1 and 2) & $50 \mu \mathrm{L}$ & ---- \\
\hline Sample & ------ & $50 \mu \mathrm{L}$ \\
\hline \multicolumn{3}{|c|}{ Mix. incubate for 5 minutes at $37^{\circ} \mathrm{C}$} \\
\hline Reagent 2 & $50 \mu \mathrm{L}$ & $50 \mu \mathrm{L}$ \\
\hline
\end{tabular}

\section{CALCULATIONS}

A1-A2 (sample)

Concentration of homocysteine $(\mu \mathrm{mol} / \mathrm{L})=$

A1-A2 (calibrator)

- Glucose - GOD POD method

- Urea - urease method

- Creatinine - enzymatic method

- Trop-I - card test

- HDL - direct

- TGL, Cholesterol - enzymatic method

\section{Statistical Methods}

All the values are calculated as the mean \pm standard deviation. P-value is calculated, and $<0.05$ is taken as significant. Fischer's F and Student T-test is used. Licensed SPSS software is used for the analysis of the data.

\section{RESULTS}

The evaluation of the conventional risk factors is given the tables 1 and 2 along with the homocysteine levels. There were 100 subjects with 60 in the study 
group. The mean homocysteine was $20.19 \pm 5.00$ $\mu \mathrm{mol} / \mathrm{L}$ in the study group whereas the control had $12.35 \pm 3.39 \mu \mathrm{mol} / \mathrm{L}$. Hence, homocysteine is significantly higher $(<0.001)$ in the study. It also had the highest specificity in this case.

Diabetes was a significant independent risk factor in this study (37\%). Fasting and postprandial blood glucose levels were elevated significantly in the study group. Smoking was highly significant with $42 \%$ of the study group being smokers. A higher SBP was observed in the study group and the control groups. HTN was not significantly associated with the disease with p-value being 0.2 in this study. Total cholesterol $(<0.001), \quad \operatorname{HDL}(<0.001), \quad \operatorname{LDL}(0.0139) \quad$ were significantly associated with the disease whereas the Triglycerides with a p-value of 0.10 did not show the significance.

Table-1: Comparision of Risk factors in Control and Study Group

\begin{tabular}{|l|l|l|l|l|}
\hline S.No & Risk factors & Idy Group $(\mathbf{n = 6 0})$ & trol Group $(\mathbf{n = 4 0})$ & P value \\
\hline 1 & Smokers & $25(42 \%)$ & $4(10 \%)$ & 0.0016 \\
\hline 2 & Family history of CAD & $17(27 \%)$ & $2(6 \%)$ & 0.0097 \\
\hline 3 & Alcohol & $14(23 \%)$ & $9(24 \%)$ & $0.9(\mathrm{~ns})$ \\
\hline 4 & Hypertension & $19(32 \%)$ & $8(20 \%)$ & $0.2(\mathrm{~ns})$ \\
\hline 5 & Total cholesterol & $195 \pm 41$ & $149 \pm 25$ & $<0.001$ \\
\hline 6 & Triglycerides & $134 \pm 27$ & $121 \pm 22$ & $0.10(\mathrm{~ns})$ \\
\hline 7 & HDL & $27 \pm 5$ & $35 \pm 4$ & $<0.001$ \\
\hline 8 & LDL & $138 \pm 15$ & $125 \pm 17$ & 0.0139 \\
\hline 9 & FBS & $144 \pm 29$ & $110 \pm 21$ & $<0.001$ \\
\hline 10 & PPBS & $187 \pm 24$ & $132 \pm 9.9$ & $<0.001$ \\
\hline 11 & Homocysteine $(\mu \mathrm{mol} / \mathrm{L})$ & $20.19 \pm 5.00$ & $12.35 \pm 3.39$ & $<0.001$ \\
\hline
\end{tabular}

Table-2: Comparison of various risk factors

\begin{tabular}{|l|l|l|l|l|l|}
\hline & Smoking & Alcohol & HTN & $\begin{array}{l}\text { Family history } \\
\text { of CAD }\end{array}$ & Homocysteine \\
\hline Sensitivity & $41.67 \%$ & $23.33 \%$ & $31.67 \%$ & $28.33 \%$ & $70.00 \%$ \\
\hline Specificity prediction & $86.00 \%$ & $77.50 \%$ & $80.00 \%$ & $95.00 \%$ & $72.50 \%$ \\
\hline $\begin{array}{c}\text { Positive } \\
\text { value }\end{array}$ & $86.21 \%$ & $60.87 \%$ & $70.37 \%$ & $89.47 \mathrm{v}$ & $79.25 \%$ \\
$\begin{array}{c}\text { Negative prediction } \\
\text { value }\end{array}$ & $50.70 \%$ & $40.26 \%$ & $43.84 \mathrm{v}$ & $46.91 \%$ & $61.70 \%$ \\
\hline Accuracy & $61.00 \%$ & $45.00 \%$ & $51.00 \%$ & $55.00 \%$ & $71.00 \%$ \\
\hline Odds Ratio & 6.4286 & 1.0483 & 1.8537 & 7.5116 & 6.1515 \\
\hline P value & 0.0016 & 0.9 & 0.2 & 0.0097 & $<0.001$ \\
\hline
\end{tabular}

The association between homocysteine and other risk factors was assessed based on the disease prevalence. Out of the 60 diseased, the combination of elevated Homocysteine and smoking is seen in 13 people while only smoking is observed in 12 people showing no significant alteration of disease prevalence upon the combination of both. Similarly, elevated homocysteine and diabetes combination is responsible for the disease in 11 people, and only diabetes was the risk factor for 11 people. Also, elevated Homocysteine and HTN in 11 people, 8 had only HTN and the family history of premature CAD is associated with increased levels of Homocysteine in 10 people and independently in 7 people. Hence, no significant association is noted between Homocysteine-other risk factor combination and the alteration of disease prevalence.

\section{DISCUSSION}

Homocysteine levels are significantly higher in the study group. These results are consistent with various other studies conducted in the South Indian population [12]. These higher levels may be attributed to the nutritional, ethnic and genetic factors like MTHFR gene [13, 14]. These higher levels prove the theory that hyper homocysteinemia is an independent risk factor for CAD. It also turned out to be the one with the highest specificity and accuracy among all the risk factors compared. The results were consistent with other studies $[15,16]$. However, the levels of folate and other vitamins were not included in the study; it can, therefore, be a limitation in concluding the hypothesis. Among all the other risk factors that were evaluated Hypertension did not show significant association [17], but the result must be interpreted with caution as the sample size of hypertensive subjects is low and nonsignificance maybe because of that. Smoking, diabetes, family history showed significant association in line with various studies [18]. There was no increased risk observed because of the presence of Homocysteine and other risk factors combination. Similar results were obtained by recent studies [19]. But some other studies showed positive association [20]. Alcoholism did not show any significance in the disease process. Among the lipid profile decreased HDL, increased LDL and 
cholesterol showed an increased predilection towards the disease, whereas the levels of triglycerides were not associated with the risk posed by the lipid content. Similar results were reported by the studies conducted recently [21]. Though there were only a few people in the control group that had elevated levels of total homocysteine, they had moderate risk producing levels according to the classification of Kang et al., [22]. It probably indicates that in the future, they have a higher chance of turning into cases. These higher levels in few of the controls could be an early sign of the disease and if proved right could be helpful in early screening and further prevention of the disease. Investigation in this perspective is required. All the results are bound by ethnic differences and small sample size. Hence they must be interpreted with caution.

\section{CONCLUSION}

This study indicates that hyper homocysteinemia is an accurate, independent risk factor for CAD. There is also a lack of altered risk posed by the conventional risk factors in the presence of elevated levels of Homocysteine. Further investigations are necessary to enquire into the benefits of administering vitamins to the risk population. Hyper homocysteinemia might even be an early sign of the disease if proven right by researching this perspective. Determination of this may give an idea of adding the measurement of Homocysteine levels in the screening process.

\section{ACKNOWLEDGEMENT}

Funded by ICMR under the Short Term Studentship (STS) program.

\section{REFERENCES}

1. Gupta, R., Mohan, I., \& Narula, J. (2016). Trends in coronary heart disease epidemiology in India. Annals of global health, 82(2), 307-315.

2. Mack, M., \& Gopal, A. (2016). Epidemiology, traditional and novel risk factors in coronary artery disease. Heart failure clinics, 12(1), 1-10.

3. Neki, N. S. (2003). Hyperhomocysteinaemia-An Independent Risk factor for Cardio-vascular Diseases. Journal, Indian Academy of Clinical Medicine, 4(1), 55.

4. Hankey, G. J., \& Eikelboom, J. W. (1999). Homocysteine and vascular disease. The lancet, 354(9176), 407-413.

5. Chacko, K. A. (1998). Plasma homocysteine levels in patients with coronary heart disease. Indian heart journal, 50(3), 295-299.

6. Mehta, M., \& Shah, J. (2012). Absence of association between serum homocysteine levels and coronary artery disease. Ind Med Gaz, 253256.

7. Weissler, A. M. (2004). Traditional risk factors for coronary heart disease. JAMA, 291(3), 299-299.

8. Kang, S. S., Wong, P. W., Cook, H. Y., Norusis, M., \& Messer, J. V. (1986). Protein-bound homocyst (e) ine. A possible risk factor for coronary artery disease. The Journal of clinical investigation, 77(5), 1482-1486.

9. Shenoy, V., Mehendale, V., Prabhu, K., Shetty, R., \& Rao, P. (2014). Correlation of serum homocysteine levels with the severity of coronary artery disease. Indian Journal of Clinical Biochemistry, 29(3), 339-344.

10. Bozkurt, E., Keles, S., Acikel, M., Islek, M., \& Ateşal, S. (2004). Plasma homocysteine level and the angiographic extent of coronary artery disease. Angiology, 55(3), 265-270.

11. Savage, D. G., Lindenbaum, J., Stabler, S. P., \& Allen, R. H. (1989). Sensitivity of serum methylmalonic acid and total homocysteine determinations for diagnosing cobalamin, choline riboflavin and troxerutin in atherosclerosis. American Journal of Medicine, 88L, 143.

12. Ganguly, P., \& Alam, S. F. (2015). Role of homocysteine in the development of cardiovascular disease. Nutrition journal, 14(1), 6.

13. Naghshtabrizi, B., Shakerian, F., Hajilooi, M., \& Emami, F. (2012). Plasma homocysteine level and its genotypes as a risk factor for coronary artery disease in patients undergoing coronary angiography. Journal of cardiovascular disease research, 3(4), 276.

14. Nishi, A., Numata, S., Tajima, A., Kinoshita, M., Kikuchi, K., Shimodera, S., ... \& Takeda, M. (2014). Meta-analyses of blood homocysteine levels for gender and genetic association studies of the MTHFR C677T polymorphism in schizophrenia. Schizophrenia bulletin, $40(5)$, 1154-1163.

15. Harish, R. B., Govindaraju, V., \& Manjunath, C. N. (2007). Risk prediction-Homocysteine in Coronary Heart Disease. Indian Journal of Clinical Biochemistry, 22(1), 18.

16. Abraham, R., John, M. J., Calton, R., \& Dhanoa, J. (2006). Raised serum homocysteine levels in patients of coronary artery disease and the effect of vitamin B12 and folate on its concentration. Indian Journal of Clinical Biochemistry, 21(1), 95.

17. Skeete, J., \& DiPette, D. J. (2017). Relationship between homocysteine and hypertension: New data add to the debate. The Journal of Clinical Hypertension, 19(11), 1171-1172.

18. Assmann, G., Cullen, P., \& Schulte, H. (2002). Simple scoring scheme for calculating the risk of acute coronary events based on the 10-year follow-up of the prospective cardiovascular Munster (PROCAM) study. Circulation, 105(3), 310-315.

19. Ranjith, R., \& Devika, P. (2017). Clinical Correlation between Plasma Homocysteine Level and Coronary Artery Disease in Indian Patients. World Journal of Cardiovascular Diseases, 7(12), 477.

20. Chamber's, J. C., Obeid, O. A., \& Refsum, H. (2000). Plasma homocysteine concentrations. 
Lancet. 1355, S23.

21. Puri, A., Gupta, O. K., Dwivedi, R. N., Bharadwaj, R. P., Narain, V. S., \& Singh, S. (2003). Homocysteine and lipid levels in young patients with coronary artery disease. $J$ Assoc
Physicians India, 51, 681-685.

22. Kang, S. S., Wook, P. W. K., \& Mallinow, M. R. (1992). Hyper homocysteinemia as a risk factor factor for occlusive vascular disease. Annual Review of rationion. 12, 279. 